Biryukov V. S. Audit of risk-management methods in respect of their acceptance of analysis medical activity. Pedagogy and Psychology of Sport. 2017;3(2):37-47. eISSN 2450-6605. DOI http://dx.doi.org/10.5281/zenodo.831674 http://apcz.umk.pl/czasopisma/index.php/PPS/article/view/PPS.2017.009

Original text

Biryukov V. S. Audit of risk-management methods in respect of their acceptance of analysis medical activity. Journal of Education, Health and Sport. 2017;7(2):625-635. eISSN 2391-8306. DOI http://dx.doi.org/10.5281/zenodo.831674

http://ojs.ukw.edu.pl/index.php/johs/article/view/4629

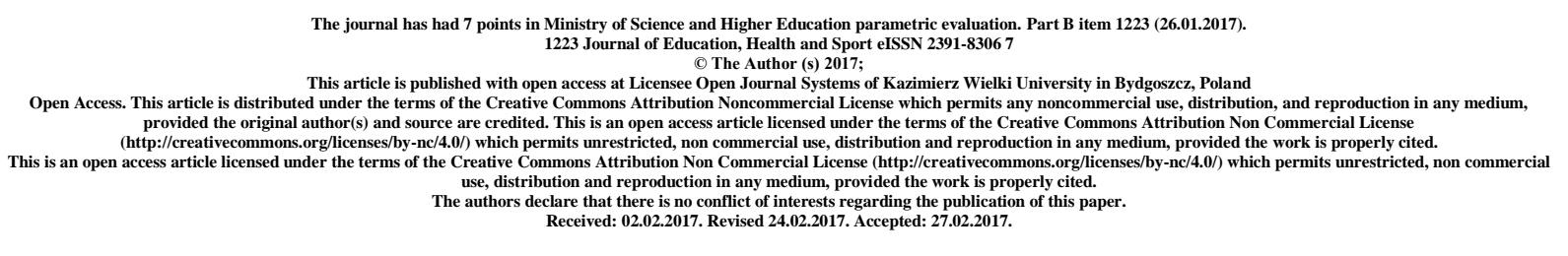

\title{
AUDIT OF RISK-MANAGEMENT METHODS IN RESPECT OF THEIR ACCEPTANCE OF ANALYSIS MEDICAL ACTIVITY
}

\author{
V.S. Biryukov
}

\section{Odessa National Medical University}

\begin{abstract}
The work is devoted to the analysis of accessibility, usefulness and the possibilities of introducing a number of risk management methods into medical institutions on the basis of the choice of heads medical institutions, after getting to know them with the main methods, proposed by the ISO 31000: 2009 standard. The conducted research has shown advantages of methods of "brainstorming" and the analysis of cause-effect relations by heads of medical institutions.

Keywords: ISO 31000: 2009 standard, risk management, medicine, quality management
\end{abstract}


УДК 616.24-022: 338

\title{
АУДИТ МЕТОДІВ РИЗИК-МЕНЕДЖМЕНТУ ЩОДО ЇХ ПРИЕМЛИМОСТЬ ПРИ АНАЛІЗІ МЕДИЧНОї ДІЯЛЬНОСТІ
}

\author{
В. С. Бірюков
}

\section{Одеський національний медичний університет}

\begin{abstract}
Рeфepat
Робота присвячена аналізу доступності, корисності і можливостям впровадження в лікувальні установи ряду методів ризик-менеджменту на основі вибору керівників медичних установ, після знайомства їх з основними методами, пропонованими стандартом ISO 31000: 2009. Проведене дослідження показало переваги методів «мозкового штурму» i аналізу причинно-наслідкових зв'язків керівниками медичних установ.

Ключові слова: стандарт ISO 31000: 2009. управління ризиками, медицина, управління якістю
\end{abstract}

АУДИТ МЕТОДОВ РИСК-МЕНЕДЖМЕНТА В ОТНОШЕНИИ ИХ ПРИЕМЛИМОСТИ ПРИ АНАЛИЗЕ МЕДИЦИНСКОЙ ДЕЯТЕЛЬНОСТИ

\section{В. С. Бирюков}

\section{Одесский национальный медицинский университет}

\section{Реферат}

Работа посвящена анализу доступности, полезности и возможностям внедрения в лечебные учреждения ряда методов риск-менеджмента на основе выбора руководителей медицинских учреждений, после знакомства их с основными методами, предлагаемыми стандартом ISO 31000:2009. Проведенное исследование показало преимущества методов «мозгового штурма» и анализа причинно-следственных связей руководителями медицинских учреждений. 
Ключевые слова: стандарт ISO 31000:2009, управление рисками, медицина, управление качеством

Последняя версия международного стандарта качества ISO 9001:2015, в отличие от прежней версии, стала включать дополнительное требование к аудируемой организации о необходимости проведения анализа рисков и управления рисками [1]. Риски для здоровья человека, как потенциальные опасности возникновения инфекционных или соматических заболеваний, хорошо известны медицинской общественности, и по отношению к ним выработаны эффективные профилактические меры.

Однако в данном стандарте идет речь об особых рисках - рисках человеческой деятельности в медицинской практике, реализация которых приводит зачастую к драматическим последствиям, носящим различные определения: Чаще всего такими рисками в медицине являются: врачебные ошибки (medical errors), невнимательность медицинского персонала, лекарственные осложнения, отсутствие необходимых медикаментов, расхождение диагнозов, травматизм во время лечебно-диагностических манипуляций и др. Исключение или нейтрализация подобных злополучных «человеческих факторов» рисков является, с современной точки зрения, важным направлением в повышении качества оказываемых медицинских услуг, в усилении конкурентоспособности медицинского учреждения.

Данная работа посвящена процессу эффективного включения риск-менеджмента в практику общей системы управления медицинской организацией, что определяет её актуальность.

Целью настоящего исследования является выбор оптимального метода рискменеджмента для внедрения в деятельность учреждений здравоохранения (УЗ)

Методологической основой исследования явились требования международного стандарта ISO 31000:2009 «Риск-менеджмент - принципы и руководства»[2] и положения, сформулированные Европейским региональным бюро ВО3 «Управление безопасностью пациентов»в 2005 г. [3].

В работе использован ряд терминов в интерпретации вышеуказанных документов.

Риск - Влияние неопределенности на цели [2; п.2.1].

Риск-менеджмент - скоординированные действия для того, чтобы направлять и контролировать организацию в отношении рисков [2; п.2.2]. 
Владелец риска - лицо или объект, несущий ответственность за управление рисками $[2 ;$ п.2.7].

Процесс управления рисками - систематическое применение политики менеджмента, процедур и практик по отношению к коммуникации, консалтингу, установлению контекста, а также идентификации, анализу, оценке, исследования, мониторинга и анализа риска[2; п.2.8].

Инцุидент, происшествие (incident) - неожиданное и непреднамеренное событие, которое привело к причинению вреда пациенту или медицинскому персоналу, включая смерть, инвалидность, повреждение, заболевание и т.д. [3].

Неблагоприятное событие (adverseivent) - вред здоровью пациента, связанный с оказанием медицинской помощи (а не с осложнением уже имеющегося заболевания или травмы при условии адекватного лечения [3].

Ошибка (error) - дефекты, упущения, ошибки, нарушения, которые привели к инциденту [3].

Рискованная ситуация или промах (nearmisses) - когда действия или бездействия медицинского персонала могли бы привести к нанесению вреда пациенту, но это событие не реализовалось в результате вовремя предпринятых профилактических мер или просто благодаря счастливой случайности [3].

Основная часть. Существующие методы риск-менеджмента имеют ряд особенностей, позволяющих различным организациям выбрать наиболее подходящие из них в зависимости от сложности управляемых процессов, вредностей окружающей рабочей среды, опыта сотрудников в области управления качеством предоставляемых услуг [4].

Выбор того или иного метода риск-менеджмента руководством УЗ может зависеть от различных факторов:

- возможность получения количественных характеристик присутствующих в УЗ рисков;

- трудности в определении характера и степени определенности факторов риска;

- степени подготовленности персонала для восприятия инновационного подхода в управлении рисками; 
- достаточности ресурсного обеспечения для проведения оценочных мероприятий и устранений потенциальных рисков.

Оценка степени доступности разнообразных методов риск-менеджмента для руководителей различных лечебных учреждений проводилась на кафедре социальной медицины, медицинского права и менеджмента ОНМедУ в 2015-2016 гг. путем анализа самостоятельных работ руководителей УЗ - слушателей курсов повышения квалификации по циклу «Социальная медицина и организация здравоохранения». Занятия включали 4 часовый лекционный материал о сущности системы менеджмента качества, основанной на требованиях стандартов серии ISO 9000, 8-часовые семинарские занятия по усвоению предлагаемых слушателям методов риск-менеджмента (см. табл. №1), а также самостоятельную «домашнюю» работу по составлению программ риск-менеджмента, адаптированных к УЗ, в которых работают слушатели.

Таблица 1

Характеристика различных методов риск-менеджмента

\begin{tabular}{|c|c|}
\hline $\begin{array}{c}\text { Методы } \\
\text { оценки риска }\end{array}$ & Сущность, сильные и слабые стороны метода [4] \\
\hline 1 & 2 \\
\hline \multirow{3}{*}{$\begin{array}{l}\text { «Мозговой } \\
\text { шттурм» } \\
{[4, \text { c. } 22-23]}\end{array}$} & $\begin{array}{l}\text { Сущность метода . Методика, которая способствует свободному } \\
\text { обсуждению и его поощрению в группе осведомленных лиц для } \\
\text { идентификации потенциальных видов отказов и связанных с ними } \\
\text { опасностей, рисков, критериев принятия решений и (или) способов } \\
\text { обработки. }\end{array}$ \\
\hline & $\begin{array}{l}\text { Сильные стороны. Поощряет творческое мышление, способствует } \\
\text { выявлению новых рисков и оригинальных решений; вовлекает } \\
\text { ключевые заинтересованные стороны и содействует всеобщему обмену } \\
\text { информацией; прост в применении и не требует больших затрат } \\
\text { времени }\end{array}$ \\
\hline & $\begin{array}{l}\text { Слабые стороны. Требует опыта и осведомленности от участников } \\
\text { исследования; метод не является структурированным; недостаточная } \\
\text { мотивация специалистов с ценными идеями к обсуждению. }\end{array}$ \\
\hline \multirow{3}{*}{$\begin{array}{l}\text { Метод } \\
\text { Делфи } \\
{[4, \text { с.24] }}\end{array}$} & $\begin{array}{l}\text { Сущность метода. Процедура достижения достоверного консенсуса } \\
\text { мнений группы экспертов, работающих индивидуально и анонимно }\end{array}$ \\
\hline & $\begin{array}{l}\text { Сильные стороны. более вероятно выражение непопулярных мнений; } \\
\text { все мнения имеют одинаковую весомость, что предотвращает проблему } \\
\text { доминирования мнений отдельных экспертов; получение права } \\
\text { собственности на результаты; отсутствие необходимости собирать всех } \\
\text { экспертов в одном месте и в одно время. }\end{array}$ \\
\hline & $\begin{array}{l}\text { Слабые стороны: Метод Дельфи является трудоемким и затратным по } \\
\text { времени. Участники должны быть в состоянии точно и ясно выразить }\end{array}$ \\
\hline
\end{tabular}


Продолжение Таблищь 1

\begin{tabular}{|c|c|}
\hline 1 & 2 \\
\hline \multirow{3}{*}{$\begin{array}{c}\text { Предваритель } \\
\text { ный анализ } \\
\text { опасностей } \\
\text { (Preliminary } \\
\text { Hazard Analysis } \\
\text { - PHA) } \\
\text { [4, с.25-26] }\end{array}$} & $\begin{array}{l}\text { Сущность метода. является простым индуктивным методом анализа, } \\
\text { цель которого состоит в идентификации опасностей, опасных ситуаций } \\
\text { и событий, которые могут нарушить работу или нанести вред данному } \\
\text { виду деятельности, оборудованию или системе. РНА обычно } \\
\text { выполняют на ранних стадиях разработки проекта в условиях } \\
\text { недостатка информации о деталях проекта или рабочих процессов. }\end{array}$ \\
\hline & $\begin{array}{l}\text { Сильные стороны. Метод РНА можно использовать в ситуации } \\
\text { ограниченной информации. Метод позволяет исследовать риск на самых } \\
\text { ранних стадиях жизненного цикла системы. }\end{array}$ \\
\hline & $\begin{array}{l}\text { Слабые стороны. Метод РНА предоставляет только предварительную } \\
\text { информацию; он не является всесторонним методом и не может } \\
\text { обеспечить подробную информацию об опасных событиях и способах } \\
\text { их предотвращения. }\end{array}$ \\
\hline \multirow{3}{*}{$\begin{array}{l}\text { Контрольные } \\
\text { листы } \\
{[4, \text { c.25] }}\end{array}$} & $\begin{array}{l}\text { Сущность метода. Контрольные листы представляют собой перечни } \\
\text { опасностей, рисков или отказов средств управления, которые обычно } \\
\text { разрабатывают на основе полученного ранее опыта, результатов } \\
\text { предыдущей оценки риска или результатов отказов, произошедших в } \\
\text { прошлом. }\end{array}$ \\
\hline & $\begin{array}{l}\text { Сильные стороны. Контрольные листы могут использовать лица, не } \\
\text { являющиеся экспертами. Если контрольные листы хорошо } \\
\text { разработаны, то они объединяют разнообразные виды экспертных } \\
\text { оценок в простую для использования форму оценки. Контрольные } \\
\text { листы обеспечивают то, что основные проблемы не упущены. }\end{array}$ \\
\hline & $\begin{array}{l}\text { Слабые стороны. Работа с контрольными листами часто сдерживает } \\
\text { свободу мыслей при идентификации опасностей. Контрольные листы } \\
\text { используют для исследования «известных знаний», но не «известного } \\
\text { незнания» или «неизвестного незнания». Применение контрольных } \\
\text { листов поощряет формальное поведение персонала по принципу } \\
\text { «поставить галочку». Метод основан на наблюдениях, поэтому } \\
\text { существует устойчивая тенденция не видеть или не замечать проблемы. }\end{array}$ \\
\hline
\end{tabular}




\begin{tabular}{|c|c|}
\hline $\begin{array}{c}\text { Исследование } \\
\text { НАZOP } \\
\text { (Hazard and } \\
\text { Operability } \\
\text { Study) } \\
\text { [4, c.26-29] }\end{array}$ & $\begin{array}{l}\text { Сущность метода. Исследование НAZOР представляет собой структу- } \\
\text { рированный и систематизированный анализ запланированных или су- } \\
\text { ществующих процессов, процедур или систем. НAZOP - метод иденти- } \\
\text { фикации опасностей и риска для людей, оборудования, окружающей } \\
\text { среды и/или достижения целей организации. От группы исследования } \\
\text { НАZОР обычно ожидают по возможности конкретных решений по об- } \\
\text { работке риска.НАZОР - это качественный метод, основанный на ис- } \\
\text { пользовании управляющих слов, которые помогают понять, почему } \\
\text { цели готовящегося проекта или условия функционирования не могут } \\
\text { быть достигнуты на каждом этапе проекта, процесса, процедуры или } \\
\text { системы. Исследование НAZОР обычно выполняет междисциплинарная } \\
\text { группа в течении нескольких заседаний. }\end{array}$ \\
\hline
\end{tabular}

Продолжение Таблищьь 1

\begin{tabular}{|c|c|}
\hline 1 & 2 \\
\hline \multirow[t]{2}{*}{$\begin{array}{l}\text { Исследование } \\
\text { НАZOP } \\
\text { (Hazard and } \\
\text { Operability } \\
\text { Study) } \\
\text { [4, c.26-29] }\end{array}$} & $\begin{array}{l}\text { Сильные стороны. Метод обеспечивает систематическое и полное } \\
\text { исследование системы, процесса или процедуры. К работе } \\
\text { привлекаются эксперты по смежным направлениям деятельности, } \\
\text { включая специалистов, имеющих практический производственный опыт } \\
\text { работы, которым, вероятно, придется внедрять рекомендации по } \\
\text { обработке риска. Метод помогает в выборе решения и способов } \\
\text { обработки риска. Метод применим к широкому диапазону систем, } \\
\text { процессов и процедур. Он позволяет точно рассмотреть причины и } \\
\text { последствия ошибок исполнителей. В рамках процесса НАZOР } \\
\text { проходит регистрация всех записей, что позволяет обеспечить } \\
\text { объективные свидетельства для дальнейшего анализа. }\end{array}$ \\
\hline & $\begin{array}{l}\text { Слабые стороны. Детальный анализ требует наличия подробной } \\
\text { документации и требований к системам, процессам или процедурам. } \\
\text { Исследование НAZOP может быть сосредоточено на нахождении } \\
\text { детальных решений, а не на пересмотре использованных основных } \\
\text { предположений (этот недостаток можно смягчить поэтапным приме- } \\
\text { нением метода). Обсуждение может быть сосредоточено на отдельных } \\
\text { проблемах проекта и не касаться широких или внешних проблем. }\end{array}$ \\
\hline \multirow{2}{*}{$\begin{array}{l}\text { Структуриров } \\
\text { анный анализ } \\
\text { сценариев } \\
\text { методом «что, } \\
\text { если?» - SWIFT } \\
\text { (Structured what- } \\
\text { if technique) } \\
\quad[4, \text { c.32-34] }\end{array}$} & $\begin{array}{l}\text { Сущность метода. Метод SWIFT - это систематизированный метод } \\
\text { исследования сценариев, основанный на командной работе, в котором } \\
\text { используют набор слов или фраз-подсказок, помогающих в процессе } \\
\text { совещания участникам группы идентифицировать опасные ситуации и } \\
\text { создать сценарий их развития. Ведущий и группа, используя } \\
\text { стандартные фразы «что, если» в сочетании с подсказками исследуют, } \\
\text { как система, элемент производственного процесса, организация или } \\
\text { процедура будут вести себя под воздействием опасного события. }\end{array}$ \\
\hline & $\begin{array}{l}\text { Сильные стороны. Метод применим ко всем формам элементов, } \\
\text { систем, ситуаций, условий, организаций и видов деятельности. Метод } \\
\text { требует минимальной подготовки группы исследований, он достаточно } \\
\text { быстро помогает идентифицировать основные опасности, которые }\end{array}$ \\
\hline
\end{tabular}




\begin{tabular}{|l|l|l|}
\hline & $\begin{array}{l}\text { становятся очевидными в процессе обсуждения. Системный подход к } \\
\text { исследованию позволяет участникам увидеть реакцию системы на } \\
\text { отклонения, не ограничиваясь рассмотрением последствий отказа } \\
\text { компонентов. Метод может быть использован для идентификации } \\
\text { способов улучения процессов и систем и определения мер, } \\
\text { приводящих повышениюихнадежности.. }\end{array}$ \\
\hline Слабые стороны. Для эффективного применения данного метода \\
необходим опытный ведущий. Необходима тщательная подготовка \\
обсуждений, чтобы время совещания исследовательской группы не \\
было потрачено впустую. Если исследовательская группа не имеет \\
достаточного опыта или если система подсказок не является \\
всесторонней, то некоторые риски или опасности могут быть \\
пропущены и не идентифицированы.
\end{tabular}

Продолжение Таблищъь 1

\begin{tabular}{|c|c|}
\hline 1 & 2 \\
\hline \multirow{4}{*}{$\begin{array}{l}\text { Анализ } \\
\text { Причинно- } \\
\text { следственных } \\
\text { связей }[4, \text { с. } 45- \\
47]\end{array}$} & $\begin{array}{l}\text { Сущность метода. это структурированный метод, применяемый для оп- } \\
\text { ределения возможных причин нежелательного события или проблемы. } \\
\text { Он систематизирует возможные влияющие факторы в обобщенные } \\
\text { категории таким образом, что позволяет рассматривать все возможные } \\
\text { гипотезы. Информацию представляют в виде диаграммы Исикавы } \\
\text { (называемой также «рыбья кость»), иногда - в виде древовидной схемы. }\end{array}$ \\
\hline & $\begin{array}{l}\text { Сильные стороны: привлечение компетентных экспертов и их работа } \\
\text { в группе; структурированный анализ; рассмотрение всех вероятных } \\
\text { предположений; графическое отображение результатов в простой для } \\
\text { восприятия форме; определение областей, в которых требуются } \\
\text { дополнительные } \\
\text { данные; } \\
\text { возможность }\end{array}$ \\
\hline & $\begin{array}{l}\text { предрасполагающих факторов как для благоприятных, так и для } \\
\text { нежелательных результатов. Положительное акцентирование на вопросе } \\
\text { может способствовать большей вовлеченности и заинтересованности. }\end{array}$ \\
\hline & $\begin{array}{l}\text { Слабые стороны. группа экспертов может не иметь необходимой ком- } \\
\text { петентности; методика не применяется самостоятельно, для разработки } \\
\text { рекомендаций необходимо, чтобы она применялась как часть анализа } \\
\text { первоначальной причины; методика предназначена для проведения } \\
\text { «мозгового штурма», а не отдельного анализа; разделение причинных } \\
\text { факторов на основные категории в начале анализа означает, что взаимо- } \\
\text { связи между категориями могут не рассматриваться должным образом. }\end{array}$ \\
\hline $\begin{array}{l}\text { Анализ } \\
\text { сценариев } \\
{[4 . \text { C.34-35] }}\end{array}$ & $\begin{array}{l}\text { Сущность метода заключается в процессе разработки описательных } \\
\text { моделей того, что может произойти в будущем. Он может применяться } \\
\text { для идентификации рисков посредством рассмотрения возможных ва- } \\
\text { риантов развития событий и исследования их возможных последствий. } \\
\text { Группы сценариев, отражающих, например, «наилучший случай», «наи- } \\
\text { худший случай» и «ожидаемый случай», могут применяться для анализа } \\
\text { возможных последствий и их вероятностей для каждого сценария как } \\
\text { форма анализа чувствительности при проведении анализа риска. }\end{array}$ \\
\hline
\end{tabular}




\begin{tabular}{|l|l|}
\hline Сильные стороны. Метод рассматривает ряд возможных ситуаций в \\
будущем, что может быть более предпочтительным по сравнению с тра- \\
диционном подходом, основанным на прогнозах разной степени долг-- \\
временности, в которых предполагается, на основании накопленных \\
данных, что будущие события, вероятно, будут продолжаться, следуя \\
прошлыми тенденция. Это важно для ситуаций, когда имееся недо- \\
статочно текущей информации, на которой можно основывать прогноз, \\
или в которых рассматриваются риски в более отдаленном будущем. \\
\hline $\begin{array}{l}\text { Слабые стороны. Основные затруднения могут быть связаны со сте- } \\
\text { пенью наличия данных и способностью аналитиков и лиц, принимаю- } \\
\text { щих решения, разрабатывать реалистичные сценарии, которые при- } \\
\text { годны для исследования возможных результатов. Применяемые сцена- } \\
\text { рии могут не иметь соответствующего основания; получаемые данные } \\
\text { могут быть гипотетическими, при этом не реалистичность результатов } \\
\text { может быть не выявлена. }\end{array}$ \\
\hline
\end{tabular}

Ниже приведена сводная таблица, отражающая методы риск-менеджмента, в которых идентификация рисков является возможной и обязательной, согласно требованиям стандарта ISO 31010, а также дается их характеристики и оценка возможности использования методов в деятельности УЗ.

Оценка степени усвоения слушателями цикла предложенных методов проводилась на основании свободного выбора ими методов риск-менеджмента, для анализа деятельности собственных учреждений. Эти данные дополнены сведениями на основании анкетирования, при котором слушатели должны были оценить по 5 - бальной системе доступность, полезность и реальную возможность внедрения того или иного метода в практическую деятельность руководства УЗ (см. табл. 2).

Таблица 2

Оценка доступности, полезности и возможности внедрения методов риск-менеджмента в деятельность руководства УЗ

\begin{tabular}{|c|c|c|c|c|c|}
\hline $\begin{array}{c}\text { № } \\
\Pi / \Pi\end{array}$ & $\begin{array}{c}\text { Методы } \\
\text { Риск-менеджмента }\end{array}$ & $\begin{array}{c}\text { Свободный } \\
\text { выбор } \\
(\mathrm{n}=32)\end{array}$ & $\begin{array}{c}\text { Доступность } \\
(\mathrm{n}=36)\end{array}$ & $\begin{array}{c}\text { Полезность } \\
(\mathrm{n}=36)\end{array}$ & $\begin{array}{c}\text { Возможность } \\
\text { внедрения } \\
(\mathrm{n}=36)\end{array}$ \\
\hline 1 & «Мозговой штурм» & $1(3,12 \%)$ & $4,31 \pm 0,60$ & $3,64 \pm 0,62$ & $4,25 \pm 0,65$ \\
\hline 2 & $\begin{array}{c}\text { Метод } \\
\text { Делфи }\end{array}$ & $3(9,37 \%)$ & $3,22 \pm 0,44$ & $2,61 \pm 0,53$ & $1,94 \pm 0,56$ \\
\hline 3 & $\begin{array}{c}\text { Предварительный } \\
\text { анализ опасностей }\end{array}$ & $2(6,25 \%)$ & $3,08 \pm 0,55$ & $2,42 \pm 0,63$ & $2,28 \pm 0,65$ \\
\hline 4 & Контрольные листы & $0(0,00 \%)$ & $3,17 \pm 0,48$ & $3,42 \pm 0,64$ & $2,78 \pm 1,00$ \\
\hline 5 & Исследование & $2(6,25 \%)$ & $2,53 \pm 0,78$ & $2,92 \pm 0,31$ & $2,69 \pm 0,62$ \\
\hline
\end{tabular}




\begin{tabular}{|c|c|c|c|c|c|}
\hline & НАZОР & & & & \\
\hline 6 & $\begin{array}{c}\text { Структурированный } \\
\text { анализ сценариев }\end{array}$ & $2(6,25 \%)$ & $3,42 \pm 0,82$ & $2,86 \pm 0,47$ & $2,25 \pm 0,59$ \\
\hline 7 & $\begin{array}{c}\text { Анализ причинно- } \\
\text { следственных связей }\end{array}$ & $17(53,12 \%)$ & $4,14 \pm 0,84$ & $3,81 \pm 0,57$ & $4,53 \pm 0,56$ \\
\hline 8 & Анализ сценариев & $5(15,62 \%)$ & $2,86 \pm 0,65$ & $2,61 \pm 0,46$ & $2,31 \pm 0,68$ \\
\hline & Всего & $\mathbf{3 2}(100 \%)$ & & & \\
\hline
\end{tabular}

Как показало проведенное исследование, большинство руководителей для самостоятельной работы выбрали метод анализа причинно-следственных связей с его графическим исполнением. Никто не воспользовался методом контрольных листов. Очевидно, самостоятельная работа руководителей, не предполагает группового участия сотрудников, чем объясняется единичный выбор методов «мозгового штурма», Предварительного анализа опасностей, исследования НAZOP.

Иные сведения получены при изучении анкетных данных. Так, по мнению руководителей УЗ по доступности освоения методов риск-менеджмента наиболее доступными отмечены «мозговой штурм» и анализ причинно-следственных связей. Наименее доступными названы исследование HAZOP и анализ сценариев.

При оценке полезности предложенных методов преимущество было отдано анализу причинно-следственных связей, «мозговому штурму» и контрольным листам. Наименее полезным оценен метод предварительного анализа опасностей.

При оценке возможностей внедрения методов риск-менеджмента в практику управляемых учреждений, руководители УЗ первые места отдали анализу причинноследственных отношений и «мозговому штурму». Малоперспективными методами внедрения по данным опрашиваемой группы явились методы Делфи, структурированного анализа сценариев и предварительный анализ опасностей.

Заключение. Проведенное исследование показало заинтересованность руководства У3 в освоении новых методов управления на основе риск- менеджмента. Вместе с тем, возможности существующих программ повышения квалификации руководителей УЗ не позволяют им освоить в полном объеме все методы риск-менеджмента. Анализ доступности, видимой полезности и возможности вредрения тех или иных методов рискменеджмента в управленческую практику УЗ показывает существенное различие в мнениях руководителей. Вместе с тем, отмечается тенденция к преимущественному 
освоению наиболее наглядных, подтверждаемых графическим исполнением методов рискменеджмента: методы «мозгового штурма» и анализ причинно-следственных отношений.

\section{Использованные источники информации}

1. ISO 9001:2008 Quality management systems - Requirements (IDT)/ ГОСТ Р ИСО 9001-2008 Системы менеджмента качества. Требования// - Издание официальное. Национальный Стандарт Российской Федерации.- ГОСТ Р ИСО 31000:2010. - Москва: Стандартинформ, 2008. - 65 с.

2. ISO 31000:2009 Risk management — principles and guidelines (IDT)/ Менеджмент риска. Принципы и руководство//- Издание официальное. - Национальный Стандарт Российской Федерации.- ГОСТ Р ИСО 31000:2010. - Москва: -Стандартинформ, 2012. $19 \mathrm{c}$.

3. ВОЗ. Восьмой форум по вопросам будущего. Управление безопасностью пациентов. - Копенгаген : Европейское региональное бюро ВОЗ, 2005. - 38 с.

4. СТБ ISO/IEC 31010. Менеджмент риска. Методики оценки риска /Государственный стандарт Республики Беларусь// Минск, 2010. - 79 с.

\section{References}

1. ISO 9001:2008 Quality management systems - Requirements (IDT)/ GOST R ISO 9001-2008 Sistemy menedzhmenta kachestva. Trebovaniya////- Izdaniye ofitsial'noye. Natsional'nyy Standart Rossiyskoy Federatsii.- GOST R ISO 31000:2010. - Moskva: Standartinform, 2008. $-65 \mathrm{~s}$.

2. ISO 31000:2009 Risk management — principles and guidelines (IDT)/ Menedzhment riska. Printsipy i rukovodstvo//- Izdaniye ofitsial'noye. - Natsional'nyy Standart Rossiyskoy Federatsii.- GOST R ISO 31000:2010. - Moskva: -Standartinform, 2012. - 19s.

3. VOZ. Vos'moy forum po voprosam budushchego. Upravleniye bezopasnost'yu patsiyentov. - Kopengagen : Yevropeyskoye regional'noye byuro VOZ, 2005. - 38 s.

4. STB ISO/IEC 31010. Menedzhment riska. Metodiki otsenki riska /Gosudarstvennyy standart Respubliki Belarus'// Minsk, 2010. - 79 s. 